\title{
Erratum to "Assessment of calving progress and reference times for obstetric intervention during dystocia in Holstein dairy cows" (J. Dairy Sci. 94:5494-5501)
}

\section{G. M. Schuenemann, I. Nieto, S. Bas, K. N. Galvão, and J. Workman}

The footnotes on the title page were incorrectly assigned. The corresponding author of this article is G. Schuenemann (schuenemann.5@osu.edu). The current address for K. N. Galvão is Department of Large Animal Clinical Sciences, College of Veterinary Medicine, University of Florida, Gainesville, FL 32610 (erroneously assigned to G. M. Schuenemann).
The journal regrets the error.

\section{REFERENCES}

Schuenemann, G. M., I. Nieto, S. Bas, K. N. Galvão, and J. Workman. 2011. Assessment of calving progress and reference times for obstetric intervention during dystocia in Holstein dairy cows. J. Dairy Sci. 94(11):5494-5501. 